\title{
SÍNTESE E CARACTERIZAÇÃO FISICO-QUÍMICA E ESTRUTURAL DO COMPOSTO CANDIDATO A IMUNOMODULADOR LPSF/JB-11
}

\author{
J. F. BRANCO-JÚNIOR ${ }^{1}$, I. R. PITTA ${ }^{1}$, M. R. GALDINO-PITTA ${ }^{1}$ \\ ${ }^{1}$ Universidade Federal de Pernambuco, Núcleo de Pesquisa em Inovação Terapêutica Suelly \\ Galdino \\ E-mail para contato: branco.junior94@gmail.com
}

RESUMO - Definida como uma artropatia inflamatória crônica, a gota se desenvolve em cerca de 5\% dos pacientes com hiperuricemia sustentada e apresenta como principal característica dores intensas durante as crises inflamatórias agudas, as quais são tratadas com anti-inflamatórios esteroides, não esteroides ou colchicina, medicamentos com aplicações bastante limitadas devido aos seus efeitos colaterais. Diante das novas evidências da participação do PPAR- $\gamma$ no controle do processo inflamatório da gota, despertou-se o interesse no desenvolvimento de novas moléculas agonistas do PPAR- $\gamma$, como as tiazolidinas, visando sua utilização como alternativa terapêutica. Desta forma, o presente estudo teve como objetivo sintetizar um derivado tiaziolidinico através de quatro etapas reacionais e o caracteriza-lo estruturalmente por meio da técnica de CLAE e GC-MS visando sua futura aplicação no tratamento da gota. O LPSF/JB-11 apresentou rendimento de 66,75\% e elevado grau de pureza (100\%). Sua massa de $341 \mathrm{~m} / z$ (31,12\%) foi comprovada, bem como seus principais fragmentos: 119 (100\%), 152 (47,39\%) e $91 \mathrm{~m} / \mathrm{z}$ (12,87\%). Também foram identificadas características fisico-químicas importantes como $\log P(4,59)$ e Rf (0,91 Hexano/Acetato de Etila 7:3).

Palavras-chave: Tiazolidinas; Gota; GC-MS; Síntese Orgânica.

ABSTRACT - Defined as chronic inflammatory arthropathy, gout develops in about 5\% of patients with sustained hyperuricemia and presents as main characteristic intense pain during acute inflammatory crises, which are treated with steroid anti-inflammatory drugs, non-steroids or colchicine, medications with very limited applications due to its side effects. In view of the new evidence of the participation of PPAR-y in the control of the inflammatory process of gout, interest was aroused in the development of new PPAR- $\gamma$ agonist molecules, such as thiazolidines, aiming at its use as a therapeutic alternative. Thus, the present study synthesized a thiazolidinedione derivative through four reactional steps and characterized it structurally through the CLAE and GC-MS technique aiming at its future application in the treatment of gout. LPSF/JB-11 showed yield of $66.75 \%$ and high purity $(100 \%)$. Its mass of $341 \mathrm{~m} / z(31.12 \%)$ was proven, as well as its main fragments: $119(100 \%), 152(47,39 \%)$ and $91 \mathrm{~m} / \mathrm{z}(12,87 \%)$. Important physical-chemical characteristics such as $\log P(4,59)$ and $R f(0,91$ Hexane/Ethyl Acetate 7:3) have also been identified. 
Keywords: Thiazolidines; Gout; Immunomodulation; Organic Synthesis.

\section{INTRODUÇÃO}

Apesar da gota ser uma das doenças mais antigas relatadas pelo homem, seu tratamento, principalmente da fase aguda, permanece como um desafio. Caracterizada por dor intensa, rubor e calor devido a deposição de cristais de monourato de sódio (MSU) nos tecidos articulares e periarticulares, a gota é uma artropatia crônica desencadeada pela hiperuricemia sustentada em pacientes susceptíveis. Mas ainda que a fase aguda seja autolimitada (termina entre 7-10 dias após o início da crise), o uso de anti-inflamatórios é essencial para minimizar os seus sintomas, sendo os medicamentos disponíveis, contudo, de uso bastante limitado devido a restrições quanto a sua administração em pacientes com comorbidades comuns a gota (ex: doenças cardiovasculares e renais) (GRASSI et al, 2014; SCHLEE et al, 2017).

Em meio a esforços para desenvolver novos anti-inflamatórios mais eficientes para o tratamento da gota, o Receptor Ativado por Proliferador de Peroxissomos Gamma (PPAR- $\gamma$ ) surge como alvo terapêutico alternativo, uma vez que está envolvido com a regulação da inflamação na doença, se mostrando mais expresso durante a crise aguda (POPA-NITA e NACCACHE, 2010). Reforçando tal fato, Chang e colaboradores (2016) demonstraram que a falta de um dos co-ativadores do PPAR- $\gamma$ promove a superexpressão de citocinas pró-inflamatórias como IL-1 $\beta$ e IL-18, demonstrando sua importância no processo regulatório da inflamação. Baseado nisso, o desenvolvimento de novas moléculas agonistas PPAR- $\gamma$ pode representar uma alternativa para o tratamento de pacientes que não podem fazer uso da terapia medicamentosa convencional.

As tiazolidinas, por sua vez, são uma classe de moléculas de anéis pentaméricos heterocíclicos bastante conhecidas pela sua atividade agonista do PPAR- $\gamma$, sendo atualmente utilizadas como antiglicêmicos (Ex: Roziglitazona e Pioglitazona), mas que possuem um grande potencial anti-inflamatório. Desta forma, o presente trabalho teve como objetivo sintetizar um novo derivado tiazolidínico através de 4 etapas reacionais visando sua futura aplicação no tratamento das crises agudas de gota, caracterizando-o estruturalmente por meio do uso da técnica de cromatografia gasosa acoplada ao espectrômetro de massas (GC-MS).

\section{MATERIAIS E MÉTODOS}

\subsection{Síntese orgânica e caracterização fisico-química}

Para obtenção dos derivados tiazolidínicos 5-arilideno-3-benzil-substituídos LPSF/JB-11 e LPSF/JB-12 foram realizadas 4 etapas reacionais (1-Ciclização; 2- $N$ Alquilação; 3-Condensação de Knoevenagel; 4-Adição de Michael). A Ciclização foi realizada diluindo quantidades equimolares de ácido cloroacético e Tioureia em água, sendo a solução mantida à $90^{\circ} \mathrm{C}$ por $18 \mathrm{~h}$, para obtenção do núcleo Tiazolidínico (TZD). A $N$-alquilação do LPSF-JB-1 foi realizada através de uma reação ácido-base utilizando TZD e KOH (1.2eq), solubilizados em uma mistura de metanol e acetonitrila (1:3) por 30 minutos à temperatura ambiente (T.A). Em seguida foi adicionado o Haleto de arila em quantidade equimolar e a solução foi mantida à $60^{\circ} \mathrm{C}$ por $2 \mathrm{~h}$. Para obtenção do LPSF/IP foi utilizada a reação de condensação de Knoevenagel, a qual foi executada solubilizando quantidades equimolares do aldeído aromático e cianoacetato de etila, juntamente com o catalizador morfolina $(0,2 \mathrm{eq})$, em Toluneno, sendo a reação mantida à $110^{\circ} \mathrm{C}$ por $4 \mathrm{~h}$. A Adição de Michael foi a última etapa para obtenção dos LPSF/JBs, sendo realizada 
através da diluição de concentrações equimolares de LPSF/IP e LPSF/JB-1 em etanol, além de 0.2 eq de morfolina, sendo a solução mantida à $60^{\circ} \mathrm{C}$ por $4 \mathrm{~h}$. Após verificação da sua pureza e da sua massa pelas técnicas de CLAE e GC-MS, respectivamente, o LPSF/JB-11 teve seu ponto de fusão identificado por meio do modelo de equipamento M-560 (Buchi), bem como teve seu logP estipulado utilizando o programa ChemDraw. O Fator de Retenção (Rf) foi obtido através de cromatografia em camada delgada utilizando solução de Hexano/Acetato de etila na proporção de 7:3 como fase móvel e placas de sílica gel (Sigma-Aldrich) como fase estacionária.

\subsection{CARACTERIZAÇÃO ESTRUTURAL}

\subsubsection{Cromatografia líquida de alta eficiência (CLAE)}

Após solubilização da amostra em acetonitrila $(0,2 \mathrm{mg} / \mathrm{mL})$, a solução foi filtrada e aplicada em coluna C-18 do Cromatógrafo Líquido de Alta Eficiência modelo LCZOAT (Shimadzu) $\left(40^{\circ} \mathrm{C}\right)$, utilizando uma solução de acetonitrila $(\mathrm{ACN})$ e metanol $(\mathrm{MeOH})$ como fase móvel através do método de eluição em gradiente $(0,01 \mathrm{~min}-20 \%$ $\mathrm{MeOH} / 80 \% \mathrm{ACN} ; 15 \mathrm{~min}-80 \% \mathrm{MeOH} / 20 \% \mathrm{ANC}$; $15 \mathrm{~min}$ - fim da corrida).

\subsubsection{Cromatografia gasosa acoplada a espectrômetro de massas (GC-MS)}

A amostra foi preparada como na etapa anterior e então aplicada em coluna Restek rtx-5 30m x 25mm x 25mm de um cromatógrafo gasoso acoplado a espectrômetro de massas modelo QG-2010 (Shimadzu), utilizando Hélio como gás de arraste. A amostra foi aplicada à $320^{\circ} \mathrm{C}$, seguindo a seguinte progressão de temperatura: $0,01-1 \mathrm{~min}-40^{\circ} \mathrm{C}$; $1-7 \mathrm{~min}-180^{\circ} \mathrm{C}\left(20^{\circ} \mathrm{C} / \mathrm{min}\right) ; 7-22 \mathrm{~min}-320^{\circ} \mathrm{C}\left(10^{\circ} \mathrm{C} / \mathrm{min}\right) ; 20-40 \mathrm{~min}-320^{\circ} \mathrm{C}(\mathrm{sem}$ variação); $40 \mathrm{~min}$ - fim da corrida.

\section{RESULTADOS E DISCUSSÃO}

\subsection{Síntese e caracterização estrutural}

Como pode ser verificado na Tabela 1, o derivado tiazolidínico LPSF/JB-11 $(M=341,09)$ apresentou cristais amarelos de tonalidade clara e rendimento intermediário de $66,75 \%$, sendo este considerado satisfatório, mas passível de otimização. Seu ponto de fusão médio foi de $198,1^{\circ} \mathrm{C}$ e o $\log \mathrm{P}$ estipulado foi de 4,59 , demonstrando que o composto em questão tem baixa polaridade. Tal resultado foi confirmado através do fator de retenção, o qual foi calculado em torno de 0,91 (7:3 Hexano/Acetato de Etila). Através da cromatografia líquida de alta eficiência (CLAE), constatou-se que o LPSF/JB-11 apresentava $100 \%$ de pureza e, através do GC-MS, sua massa $\left(\mathrm{M}^{+}=341 \mathrm{~m} / \mathrm{z}\right)$ foi comprovada, como descrito na Figura 1. Tendo em vista a utilização do impacto de elétrons como método de ionização do MS, foi possível verificar seu padrão de fragmentação, o qual apresentou o íon tropílio substituído como pico base $(119 \mathrm{~m} / \mathrm{z})$, bem como o íon tropílio tradicional $(91 \mathrm{~m} / \mathrm{z})$, sendo este de menor intensidade. Outro pico de grande importância foi o de $152 \mathrm{~m} / \mathrm{z}$ relativo ao íon formado pela clivagem $\alpha$ e $\beta$ do enxofre do anel tiazolidínico (Figura 1). 
Tabela 1 - Características Físico-Químicas do Composto LPSF/JB-1

\begin{tabular}{|c|c|c|c|c|c|c|c|}
\hline Produto & P.M & Rdt (\%) & Prz $(\%)$ & Pf $\left({ }^{\circ} \mathbf{C}\right)$ & Rf & logP & Cor \\
\hline JB-11 & 341,09 & 66,75 & 100 & $198,1^{\circ} \mathrm{C}$ & 0,91 & 4,59 & Amarela \\
\hline
\end{tabular}

*PM: Peso Molecular; Rdt: Rendimento; Prz: Pureza; Pf: Ponto de Fusão; Rf: Fator de Retenção; $\operatorname{logP}$ : Coeficiente de Partição

Figura 1 - Espectro de massas contendo o padrão de fragmentação do composto LPSF/JB-11

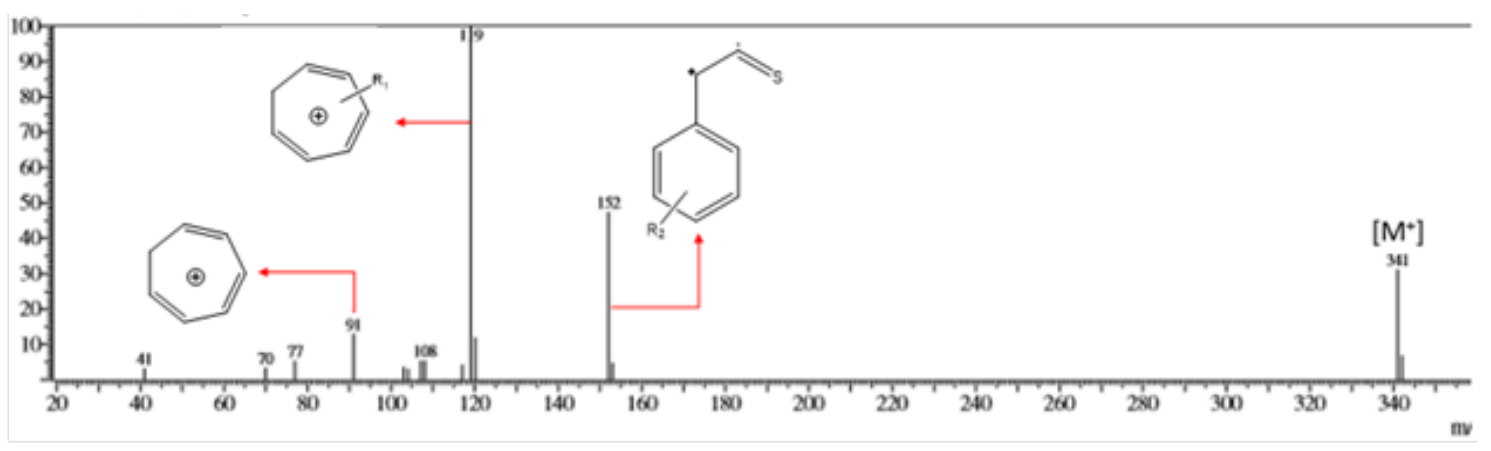

\section{CONCLUSÃO}

O composto LPSF/JB-11 se mostrou bastante estável após ionização, demonstrando a estabilidade agregada pelo intenso efeito mesomérico presente na molécula, o que também lhe confere pouca polaridade. Além disso, sua rota de síntese proporcionou um rendimento bastante satisfatório e de baixo custo, podendo o LPSF/JB11 passar para a fase de testes biológicos in vitro para avaliação da sua atividade imunomoduladora. Da mesma forma, pretende-se ainda otimizar seu processo reacional visando um futuro aumento de escala de produção.

\section{REFERÊNCIAS}

BARBOSA et al. Reduction of carrageenan-induced acute pulmonary inflammation in mice by novel thiazolidinedione derivative LPSF/RA-4. Eur. J. Pharmacol. v18, p197205, 2013.

CHANG et al. Genetic variants of PPAR-gamma coactivator 1B augment NLRP3mediated inflammation in gouty arthritis. Reumathology. v56, p457-466, 2016

GRASSI et al. Therapeutic Approaches to Chronic Hyperuricemia and Gout. High Blood Press Cardiovasc Prev. v21, p243-250, 2014.

SCHLEE et al. Crystal arthritides - gout and calcium pyrophosphate arthritis - Part 2: Clinical features, diagnosis and differencial diagnostics. Z Gerontol Geriatr. 1-6p, 2017. POPA-NITA, O.; NACCACHE, P.H. Crystal-induced neutrophil activation. Immunol Cell Biol. v88, p32-40, 2010.

\section{AGRADECIMENTOS}

UFPE, FACEPE, CNPq, CAPES e INCT-IF 